MATEC Web of Conferences 33, 06001 (2015)

DOI: $10.1051 /$ matecconf/ 20153306001

(C) Owned by the authors, published by EDP Sciences, 2015

\title{
Formation Process of Triangular Morphology of Self-Accommodation Martensite in Ti-Nb-Al Shape Memory Alloy
}

\author{
Nozomi Kamioka ${ }^{1}$, Masaki Tahara² ${ }^{2}$ Hideki Hosoda², Shuichi Miyazaki ${ }^{3}$ and Tomonari Inamura² ${ }^{*}$ \\ ${ }^{1}$ Graduate Student, Tokyo Institute of Technology, 4259 Nagatsutacho, Midori-ku, Yokohama 226-8503, Japan \\ ${ }^{2}$ Precision and Intelligence Laboratory, Tokyo Institute of Technology, 4259 Nagatsutacho, Midori-ku, Yokohama, 226-8503, Japan \\ ${ }^{3}$ Division of Materials Science, University of Tsukuba, 1-1-1 Tennodai, Tsukuba 305-8573, Japan
}

\begin{abstract}
The formation process of a habit plane variant (HPV) cluster with triangular morphology (T-cluster) in Ti$\mathrm{Nb}$-Al shape memory alloy was investigated by in-situ optical microscopy. Upon cooling the specimen, martensitic transformation occurred and two types of $\mathrm{V}$-shaped clusters and the $\mathrm{T}$-clusters were observed. Two types of $\mathrm{V}$-shaped cluster were the cluster connected by the $\{111\}$ type I twin $\left(\mathrm{V}_{\mathrm{I}}\right)$ and the cluster connected by the $<211>$ type II twin

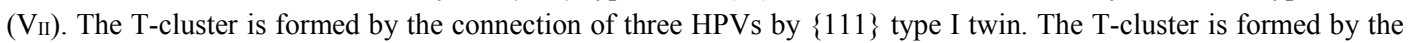
growth of the third HPV that is nucleated at the tip of a HPV in a VI-cluster and exhibits inward growth. It is suggested that the T-cluster is a derivative of the $\mathrm{V}_{\mathrm{I}}$-cluster. This growth behaviour is discussed based on the incompatibility of the clusters.
\end{abstract}

\section{Introduction}

The self-accommodation (SA) microstructure in shape memory alloys (SMAs) is constructed of the clusters that are formed by habit plane variants (HPVs). According to the phenomenological theory of martensite crystallography (PTMC), HPVs are formed to satisfy the invariant plane (IP) condition at habit plane (HP) [1-3]. In pioneering works on the martensite microstructure in SMAs, the averaged deformation gradient of the preferential HPV cluster is close to the identity matrix [4]. This criterion has been a leading principle to understand the microstructure of SMAs. However, experimental results are not always understood by this criterion as shown by Nishida et al. in Ti-Ni [5-7]. The kinematic compatibility (KC) [8] at the junction plane (JP) between HPVs is a key factor to understand the morphology of the martensite microstructure as demonstrated in some studies [9-11].

In the cubic-orthorhombic transformation [12], three HPVs are connected each other by $\{111\}$ type I twin and form a triangular morphology that has a smaller averaged strain; this morphology is termed "T-cluster" hereafter. In our recent work [13], the formation frequency of HPV clusters and its relationship between the $\mathrm{KC}$ condition were investigated in a $\beta$-titanium shape memory alloy that has cubic-orthorhombic martensitic transformation. The most common clusters were the $\mathrm{V}$-shaped clusters with $\{111\}$ type I twin ( $\mathrm{V}_{\mathrm{I}}$-cluster) or $<211>$ type II twin ( $\mathrm{V}_{\mathrm{II}}$-cluster) at JP. The T-cluster was only $9 \%$ in the observed clusters. In addition, the incompatibility that is evaluated by the magnitude of rotation to satisfy the $\mathrm{KC}$

${ }^{\mathrm{a}}$ Corresponding author: inamura.t.aa@m.titech.ac.jp condition at JP was much higher in the T-clusters $\left(\sim 1.9^{\circ}\right)$ compared to the V-shaped clusters $\left(<0.7^{\circ}\right)$. It is suggested that the T-cluster is not an essential form of HPV-cluster but is a derivative of the V-shaped clusters.

In this study, the formation process of the T-cluster in Ti-Nb-Al SMA was analysed by in-situ optical microscopy to reveal the origin of the T-cluster.

\section{Experimental procedures}

Ti-23mol\%Nb-3mol\%Al was used in this study. This alloy has martensitic transformation from parent $\beta$ phase (bcc) to $\alpha^{\prime \prime}$ martensite phase (C-centred orthorhombic) with the Au-Cd type lattice correspondence [14] and has no lattice invariant deformation [15] due to the " $\lambda_{2}=1$ " condition $[16,17]$. The habit plane is $\{755\}$ and only twelve HPVs exist in this alloy as summarized in Table $1[15]$.

High-purity starting materials of $\mathrm{Ti}(99.99 \%), \mathrm{Nb}$ $(99.9 \%)$, and $\mathrm{Al}(99.99 \%)$ were used. The ingot was fabricated by Ar arc-melting with a non-consumable Welectrode. The weight loss through the arc-melting was less than 0.1 mass $\%$ and was judged to be negligible. The ingot was wrapped in Ti-foil, encapsulated in quartz tube filled with Ar atmosphere, homogenized at $1273 \mathrm{~K}$ for $7.2 \mathrm{ks}$ and then quenched by breaking the quartz tube in iced water. Figure 1 shows the procedure of the specimen preparation. The specimens were cut by electrical discharge machining and then electro-polishing was carried out in a solution of $6 \%$ perchloric acid, 35\% butanol and $59 \%$ methanol to remove the damaged surface layer. The best temperature for the electro-

This is an Open Access article distributed under the terms of the Creative Commons Attribution License 4.0, which permits unrestricted use distribution, and reproduction in any medium, provided the original work is properly cited. Article available at $n \mathrm{ntp}: / /$ www.matec-conterences.org or http://dx.dol.org/10.1051/mateccont/20153306001 
Table 1. Notation of HPVs.

\begin{tabular}{|c|c|c|c|}
\hline HPV & HP & HPV & HP \\
\hline $1(+)$ & $(-755)$ & $1(-)$ & $(755)$ \\
\hline $2(+)$ & $(-7-55)$ & $2(-)$ & $(-75-5)$ \\
\hline $3(+)$ & $(5-75)$ & $3(-)$ & $(575)$ \\
\hline $4(+)$ & $(57-5)$ & $4(-)$ & $(-575)$ \\
\hline $5(+)$ & $(55-7)$ & $5(-)$ & $(557)$ \\
\hline $6(+)$ & $(5-57)$ & $6(-)$ & $(5-5-7)$ \\
\hline
\end{tabular}

polishing is $228 \mathrm{~K}$. The martensitic transformation temperatures of the alloy that were determined by differential scanning calorimetry are: $M_{\mathrm{s}}=291 \mathrm{~K}, M_{\mathrm{f}}=$ $249 \mathrm{~K}, A_{\mathrm{s}}=277 \mathrm{~K}$ and $A_{\mathrm{f}}=319 \mathrm{~K}$. The specimen was, therefore, in the martensitic phase during the electropolishing and the surface was flattened in the martensite state. The surface relief due to the reverse transformation existed at RT $(\sim 300 \mathrm{~K})$. The surface of the specimen was then finished by plasma-etching. The temperature of the specimen surface is around $500 \mathrm{~K}$ during the plasma-etching. The specimen surface was flattened in the parent phase. Faint relief, however, remained even after the plasma etching.

$\theta-2 \theta$ X-ray diffraction (XRD) analysis was performed at room temperature $(\mathrm{RT}, 294 \mathrm{~K})$ in order to measure the lattice parameters. The crystallographic orientation of the specimen surface was identified by electron backscatter diffraction (EBSD) analysis using a field-emission guntype scanning electron microscope (HITACHI S-4300SE) equipped with Bruker e-Flash ${ }^{1000}$ EBSD detector.

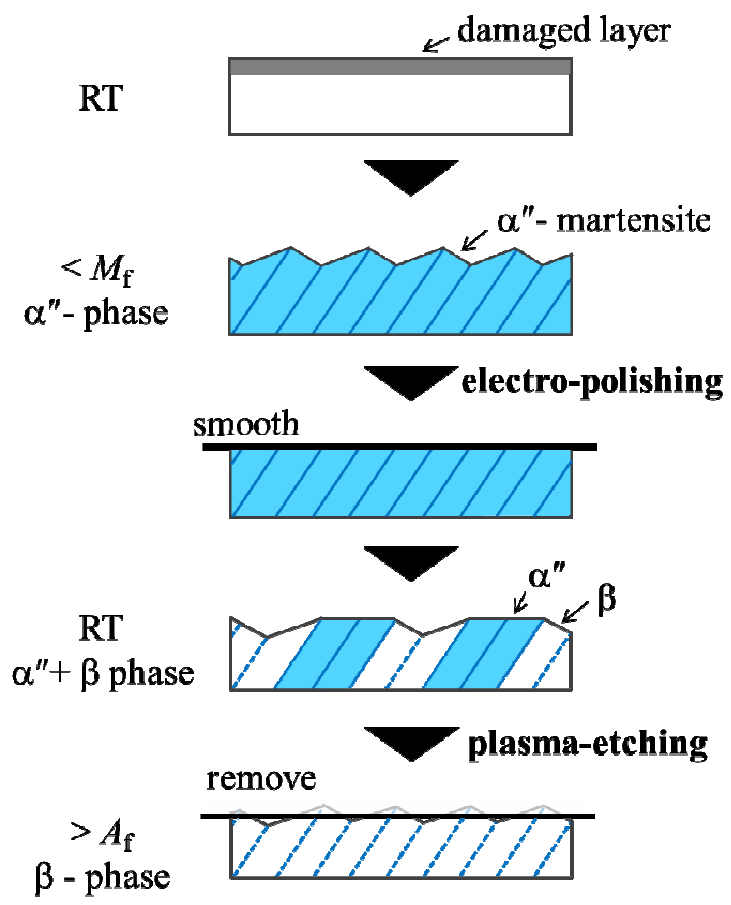

Figure 1. Procedure of the specimen preparation.
In-situ optical microscopy was made on a digital microscope equipped with a high-speed digital video camera (Keyence VW-9000). The specimen was firstly heated to $323 \mathrm{~K}$ and then cooled to $173 \mathrm{~K}$ at a cooling rate of $10 \mathrm{~K} / \mathrm{sec}$ using a temperature control chamber. The differential interference contrast microscopy was used to observe the surface relief that is generated by the martensitic transformation upon cooling. The HPV was identified by the single trace analysis based on the crystallographic orientation of the parent phase.

\section{Results and discussion}

Figure 2 shows XRD profile of the alloy. The $\beta$-phase and the $\alpha^{\prime \prime}$ - martensite phase were the apparent phases at RT. The lattice parameters were determined from this XRD profile as $a=0.3278 \mathrm{~nm}, a_{\mathrm{o}}=0.3174 \mathrm{~nm}, b_{\mathrm{o}}=$ $0.4784 \mathrm{~nm}$ and $c_{\mathrm{o}}=0.4640 \mathrm{~nm}$, where $a$ is the lattice parameter of the $\beta$ phase and $a_{\mathrm{o}}, b_{\mathrm{o}}$ and $c_{\mathrm{o}}$ are the lattice parameters of the $\alpha^{\prime \prime}$ phase. The indices with subscript o are for orthorhombic and those without subscript are for bcc, hereafter. The middle eigenvalue of the lattice deformation was 0.0009 and the HPV had no internal twin $[16,17]$.

Single trace analysis was carried out to identify HPVs. Figure 3 shows the $\{100\}$ pole figure of observed $\beta$ grain obtained from EBSD. The normal direction of the observation surface was (223). The traces of the HPs are drawn on the pole figure. HPVs were identified from the observed surface reliefs.

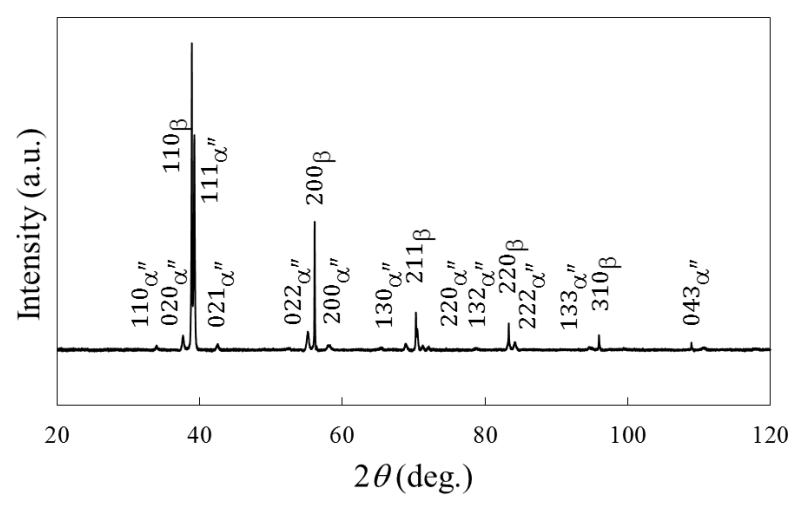

Figure 2. XRD profile of the specimen at RT.

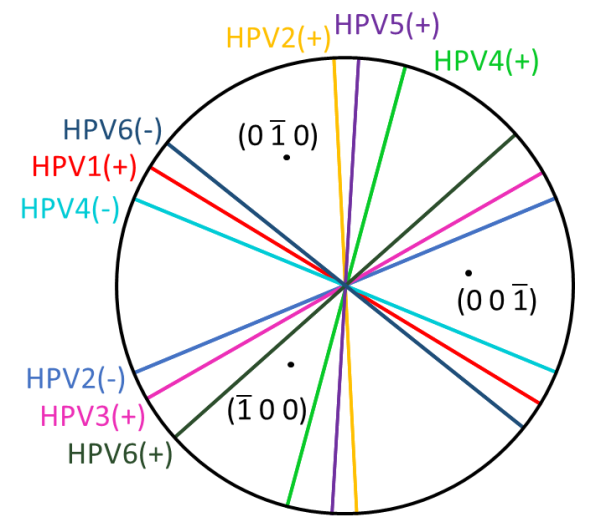

Figure 3. $\{100\}$ pole figure and the traces of the HPs. 
The two types of V-shaped clusters and the T-clusters were observed. Those two types were the cluster connected by the $\{111\}$ type I twin $\left(\mathrm{V}_{\mathrm{I}}\right)$ and the cluster connected by the $<211>$ type II twin $\left(\mathrm{V}_{\mathrm{II}}\right)$. This result is in good agreement with the result by TEM observation

(a)

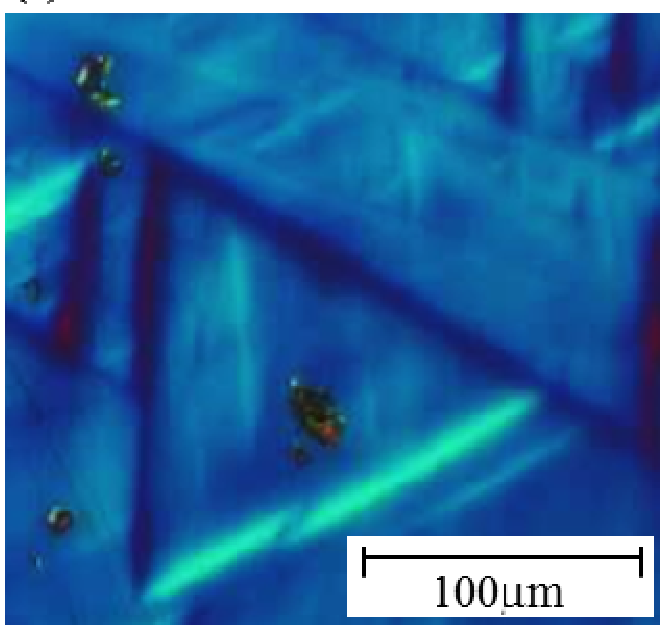

(c)

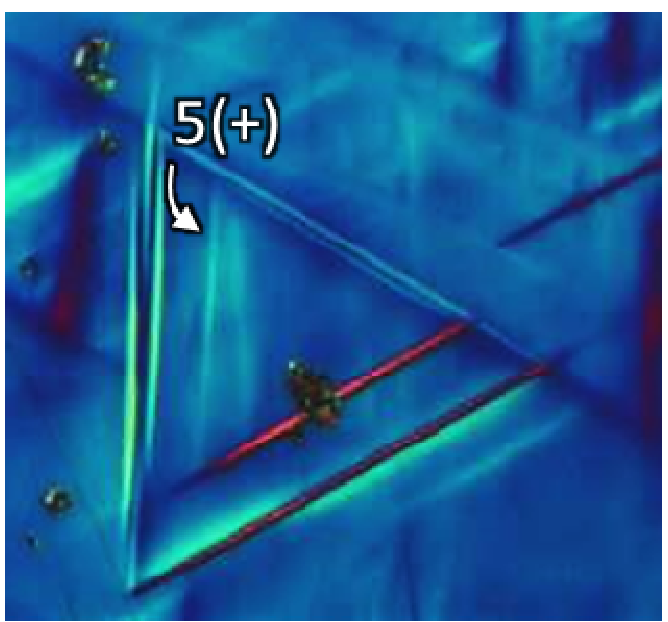

(e)

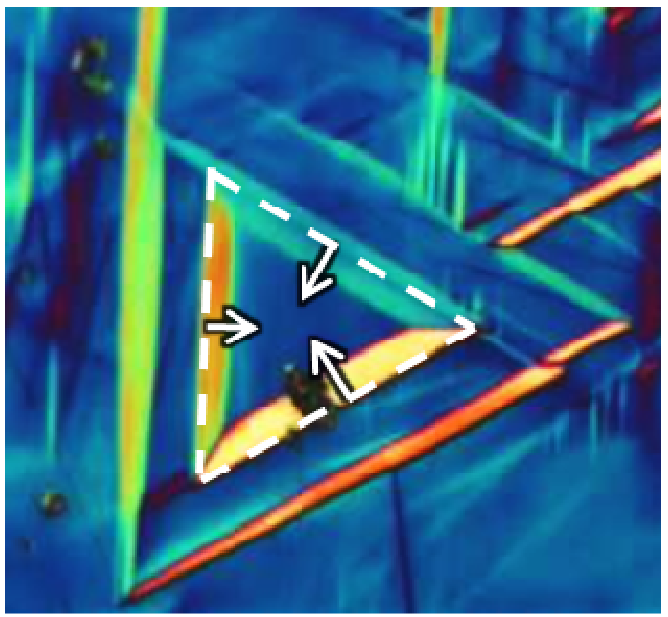

[13]. 128 clusters were identified in the observed area. All of the clusters were classified into ninety $V_{I}$ clusters, nineteen $\mathrm{V}_{\mathrm{II}}$ clusters and nineteen T-clusters. This paper focuses on the formation process of the T-clusters.

Figure 4(a) to (f) show the optical micrographs

(b)

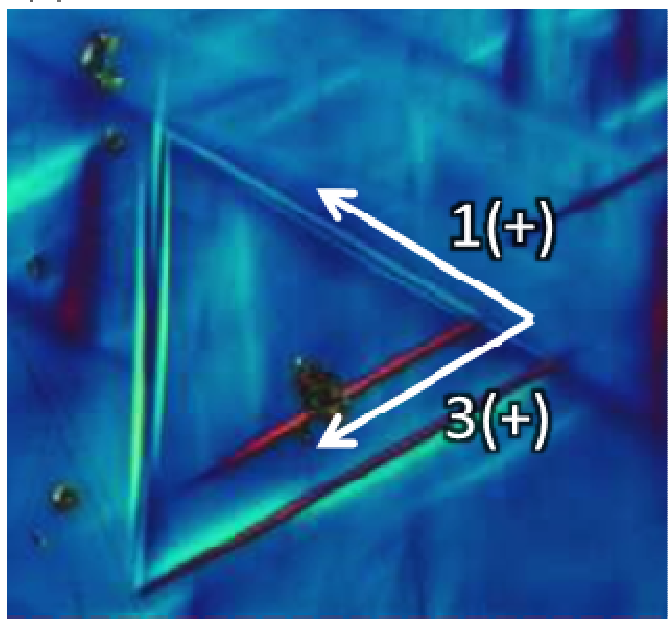

(d)

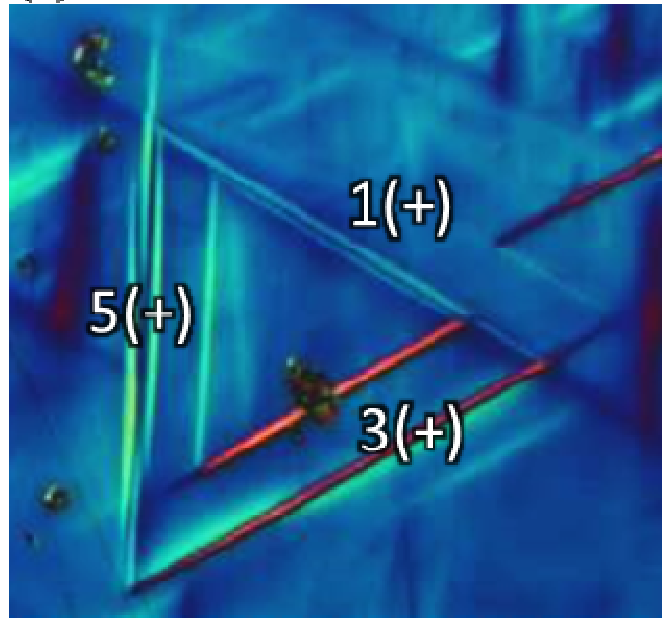

(f)

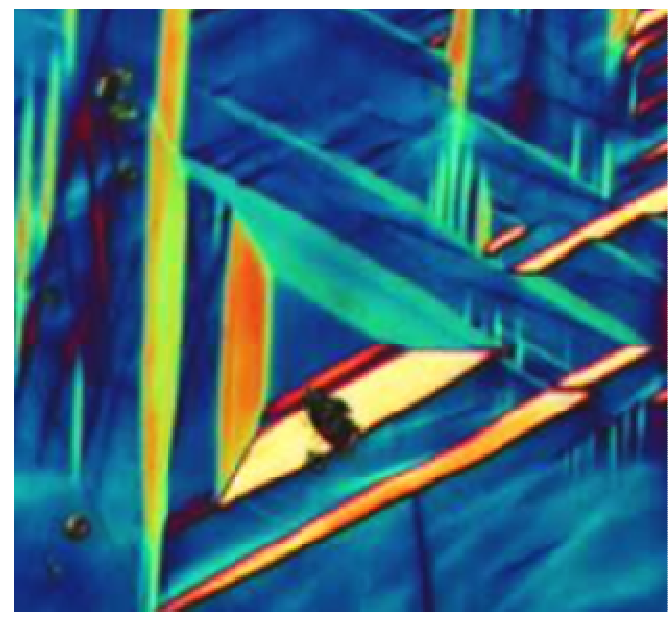

Figure 4. Snap shots of the formation process of the T-cluster upon cooling at (a) $323 \mathrm{~K}$, (b) $271 \mathrm{~K}$, (c) $270.5 \mathrm{~K}$, (d) $270 \mathrm{~K}$, (e) $250 \mathrm{~K}$ and (f) $222 \mathrm{~K}$. 
representing the formation process of one of the observed T-cluster upon cooling. The variants that formed the Tcluster were $1(+), 3(+)$ and $5(+)$. It has been reported that the junction planes of these variants are $\{111\}$ type I twin [13]. The T-cluster observed in the present study is the type identical to the T-clusters observed in cubicorthorhombic transformation in previous studies in other alloy systems $[12,18]$.

The formation process of the T-cluster is shown in detail. The starting temperature of the observation was $323 \mathrm{~K}$. At this temperature the specimen was fully $\beta$ phase and faint surface relief due to the martensites formed during the electro-polishing was seen (Fig. 4(a)). Upon cooling, the $\mathrm{V}$-shaped surface reliefs of a $\mathrm{V}_{\mathrm{I}}$-cluster appeared due to the martensitic transformation from $\beta$ to $\alpha^{\prime \prime}$-martensite (Fig. 4(b)). These reliefs were the traces of $1(+)$ and 3(+). A new relief was then appeared (Fig.4(c)). The new plate was $5(+)$. It grew and connected to the tip of $1(+)$ and $3(+)$ of the $\mathrm{V}_{\mathrm{I}}$-cluster and then a closed triangular morphology was formed (Fig. 4(d)). In some T-clusters, the third plate nucleated at the tip(s) of the plate(s) forming the $\mathrm{V}_{\mathrm{I}}$-cluster, unlike the formation process in Fig. 4. There were variations in the formation of the third plate.

Upon further cooling, the T-cluster exhibited inward growth (Fig. 4(d) and 4(e)). The inward growth stopped at $222 \mathrm{~K}$ (Fig. 4(f)) and did not complete even at $173 \mathrm{~K}$.

All junction planes in the T-cluster are considered to be connected by $\{111\}$ type I twin, according to the previous TEM study [13]. Nineteen T-clusters were analysed in this specimen and all of them exhibited the same growth process. The T-cluster is, therefore, a derivative of the $\mathrm{V}_{\mathrm{I}}$-cluster.

The averaged deformation gradient of the T-cluster is closer to the identity matrix than that of the V-shaped clusters $[12,18]$. However, the formation frequency of the T-cluster is much lower than that of the $\mathrm{V}$-shaped clusters in experiment because the incompatibility of the T-cluster is much higher than the $\mathrm{V}$-shaped clusters [13]. The incomplete inward growth is likely due to the higher incompatibility.

\section{Conclusions}

The formation process of the T-cluster in Ti-23Nb-3Al SMA was investigated by in-situ optical microscopy observation.

In the formation of the $\mathrm{T}$-cluster, firstly the $\mathrm{V}_{\mathrm{I}}$-cluster is formed, secondly the third plate is formed and then the inward growth occurs. The T-cluster is a derivative of the $\mathrm{V}_{\mathrm{I}}$-cluster.

\section{Acknowledgements}

This work was partially supported by the Advanced Low Carbon Technology Research and Development Program (JY240121) from the Japan Science and Technology Agency, Grant-in-Aid of Scientific Research (S: 26220907 and B:15H04143) and Grant-in-Aid for Young
Scientists (A: 24686077 and B: 26870194) from the Japan Society for the Promotion of Science.

\section{References}

1. J. S. Bowles and J. K. Mackenzie, Acta Metall., 2 (1954) 129-137

2. J. K. Mackenzie and J. S. Bowles, Acta Metall., 2 (1954) 138-147

3. M. S. Wechsler, D. S. Lieberman and T. A. Read, Trans. AIME, 197 (1953) 1503-1515

4. K. Otsuka and C. M. Wayman, Shape Memory Materials, Cambridge University Press, Cambridge (1998)

5. M. Nishida, T. Nishiura, H. Kawano and T. Inamura, Philos. Mag., 92 (2012) 2215-2233

6. M. Nishida, E. Okunishi, T. Nishiura, H. Kawano, T. Inamura, S. Ii and T. Hara, Philos. Mag., 92 (2012) 2234-2246

7. T. Inamura, T. Nishiura, H. Kawano, H. Hosoda and M. Nishida, Philos. Mag., 92 (2012) 2247-2263

8. J. M. Ball and R. D. James, Arch. Rat. Mech. Anal., 100 (1987) 13-52

9. J. M. Ball and D. Schryvers, J. Phys. IV (Paris) 112 (2003) 159-162

10. P. H. Boullay, D. Schryvers and J. M. Ball, Acta Mater., 51 (2003) 1421-1436

11. X. Balandraud, D. Delpueyo, M. Grediac and G. Zanzotto, Acta Mater., 58 (2010) 4559-4577

12. T. Saburi, T. Watanabe and S. Nenno, ISIJ International, 29 (1989) 405-411

13. T. Inamura, H. Hosoda and S. Miyazaki, Philos. Mag., 93 (2013) 618-634

14. D. S. Lieberman, M. S. Wechsler, T. A. Read, J. Appl. Phys., 26 (1955) 473-484

15. T. Inamura, J. I. Kim, H. Y. Kim, H. Hosoda, K. Wakashima and S. Miyazaki, Philos. Mag., 87 (2007) 3325-3350

16. J. K. Mackenzie and J. S. Bowles, Acta Metall., 5 (1957) 137-149

17. J. Cui, Y. S. Chu, O. O. Famodu, Y. Furuya, J. Hattrick-Simpers, R. D. James, A. Ludwig, S. Thienhaus, M. Wutting, Z. Zhang, I. Takeuchi, Nat. Mater., 5 (2006) 286-290

18. Y. W. Chai, H. Y. Kim, H. Hosoda, S. Miyazaki, Acta Mater., 57 (2009) 4054-4064 